\title{
A Biophysical Image Compositing Technique for the Global-Scale Extraction and Mapping of Barren Lands
}

\author{
Ram C. Sharma ${ }^{1, *}$, Ryutaro Tateishi ${ }^{1}$ and Keitarou Hara ${ }^{2}$ \\ 1 Center for Environmental Remote Sensing (CEReS), Chiba University, 1-33 Yayoi-cho, Inage-ku, \\ Chiba 263-8522, Japan; tateishi@faculty.chiba-u.jp \\ 2 Department of Informatics, Tokyo University of Information Sciences, 4-1 Onaridai, Wakaba-ku, \\ Chiba 265-8501, Japan; hara@rsch.tuis.ac.jp \\ * Correspondence: ramcsharma01@gmail.com; Tel.: +81-43-290-3832; Fax: +81-43-290-3857
}

Academic Editor: Wolfgang Kainz

Received: 17 July 2016; Accepted: 24 November 2016; Published: 30 November 2016

\begin{abstract}
As the barren lands play a key role in the interaction between land cover dynamics and climate system, an efficient methodology for the global-scale extraction and mapping of the barren lands is important. The discriminative potential of the existing soil/bareness indexes was assessed by collecting globally distributed reference data belonging to major land cover types. The existing soil/bareness indexes parameterized at the local scale did not work satisfactorily everywhere at the global level. A new technique called the Biophysical Image Composite (BIC) is proposed in the research by exploiting time-series of the multi-spectral data to capture global-scale barren land attributes effectively. The BIC is a false color composite image made up of Normalized Difference Vegetation Index (NDVI), short wave infrared reflectance, and green reflectance, which were specially selected from the highest vegetation activity period by avoiding signals from the seasonal snowfall. The drastic contrast between the barren lands and vegetation as exhibited by the BIC provides a robust extraction and mapping of the barren lands, and facilitates its visual interpretation. Random Forests based supervised classification approach was applied on the BIC for the mapping of global barren lands. A new global barren land cover map of year 2013 was produced with high accuracy. The comparison of the resulted map with an existing map of the same year showed a substantial discrepancy between two maps due to methodological variation. To cope with this problem, the BIC based mapping methodology, with a special account of the land surface phenological changes, is suggested to standardize the global-scale estimates and mapping of the barren lands.
\end{abstract}

Keywords: barren lands; Biophysical Image Composite (BIC); MODIS; random forests; visualization; global mapping; 2030 Agenda for Sustainable Development

\section{Introduction}

The barren lands are one of the fragile ecosystems of the Earth's surface. A number of socio-environmental problems such as land degradation, desertification, dust storms, draught, food security, and poverty are associated with the barren lands. The United Nations 2030 Agenda for Sustainable Development aims to achieve a land degradation-neutral world by 2030. One of the sustainable development goals of this agenda is to "protect, restore and promote sustainable use of terrestrial ecosystems, sustainably manage forests, combat desertification, and halt and reverse land degradation and halt biodiversity loss". The agenda also focus on the importance of scientifically based sound methods and indicators for monitoring and assessing the extent of desertification and land degradation [1].

Barren lands are one of the major sources of atmospheric dusts [2-4]. The dust aerosols affect the Earth's radiation budget by scattering and absorbing solar radiation and modifying the structure and 
properties of clouds [5-7]. They are sources of air pollution and are also responsible for cardiovascular and respiratory diseases [8-10]. Monitoring of the barren lands is important for better understanding of the land cover dynamics and its interaction with the climate system. It is also important for achieving the objectives of sustainable development by combating desertification and land degradation, and promoting sustainable land management.

Satellite remote sensing plays a key role in the monitoring of barren lands at the global scale due to its ability of regular observation and wide area coverage. The soil/bareness indexes as the combination of multiple spectral bands from the satellite imagery have been used for remote detection, discrimination, and mapping of the barren lands at a local scale. Rogers and Kearney [11] proposed the Normalized Difference Soil Index (NDSI) using the shortwave infrared (Swir) and near infrared (Nir) bands as shown in Equation (1). The NDSI was intended for reducing the signature variability in un-mixing the coastal marsh using Landsat TM imagery.

$$
\text { NDSI }=\frac{\text { Swir }- \text { Nir }}{\text { Swir }+ \text { Nir }}
$$

Zhao and Chen [12] developed Normalized Difference Bareness Index (NDBI) as the normalized difference between the shortwave infrared (Swir) and thermal infrared (Tir) (Equation (2)) for discriminating the bare soil areas based on Landsat TM/ETM+ images. The NDBI was used for mapping the bare areas in a coastal zone in China.

$$
\mathrm{NDBI}=\frac{\text { Swir }- \text { Tir }}{\text { Swir }+ \text { Tir }}
$$

Li and Chen [13] proposed Bareness Index by combining tasseled cap transformation based brightness and NDBI, and used for mapping of the bare soil areas in Pearl River Delta in South China. Another form of the Normalized Difference Soil Index (NDSI2) was used by Deng et al. [14] as the normalized difference between short wave infrared (Swir) and green (Green) reflectance (Equation (3)). The NDSI2 based on Landsat TM images was intended to enhance the soil information while suppressing the impervious materials and vegetation areas, and applied in few counties in the United States.

$$
\text { NDSI }=\frac{\text { Swir }- \text { Green }}{\text { Swir }+ \text { Green }}
$$

However, all the bare soil indexes as described above were used for the detection and mapping of the barren lands exclusively at the local scale. Very limited research on the remote sensing of barren land cover at the global scale is found. Recent databases that provide barren land information at the global scale are: Moderate Resolution Imaging Spectroradiometer (MODIS) Land Cover Type Product 2013 (MCD12Q1, [15]), Global Land Cover by National Mapping Organizations (GLCNMO 2008, [16]), and European Space Agency (ESA) GlobCover 2009 [17]. The MCD12Q1 product classifies the land cover types using an ensemble based supervised classification algorithm (decision tree) complemented by the training data from 1860 sites distributed across the Earth's land areas [15]. The barren land in the GLCNMO 2008 product was extracted by comparing results of the decision trees and maximum likelihood based supervised classification methods using MODIS data. The GlobCover 2009 used unsupervised clustering method and labeling by reference data as the basic method based on Medium Resolution Imaging Spectrometer (MERIS) data.

Contrary to the local scale, barren lands at the global scale are very dynamic in nature with substantial spatial and seasonal variation. The moisture, darkness, and surface roughness of barren lands, and the background with which they interact, vary considerably at the global scale. Therefore, this paper presents an assessment of the existing soil/bareness indexes for the discrimination of barren lands at the global scale by collecting globally distributed reference data. A special image compositing technique was developed for robust extraction and mapping of the barren lands at the global scale by exploiting time-series of the MODIS data. Based on new image compositing technique, the global 
barren land cover map of year 2013 was produced. The resulted map was also compared with the existing barren land map with the support of reference data.

\section{Methodology}

\subsection{Creation of Biophysical Image Composite (BIC)}

The MODIS based 8-day Level 3 Global 500 m Nadir Bidirectional Reflectance Distribution Function (BRDF)-Adjusted Reflectance (NBAR) product (MCD43A4; [18]) data of year 2013 available from the U.S. Geological Survey (USGS) was used to produce the Biophysical Image Composite (BIC). First, the Normalized Difference Vegetation Index (NDVI; $[19,20]$ ) as the normalized difference between the near infrared (Nir) and red reflectance (Red), was calculated for each 8-day period globally (Equation (4)).

$$
\mathrm{NDVI}=\frac{\mathrm{Nir}-\mathrm{Red}}{\mathrm{Nir}+\text { Red }}
$$

Then, the Maximum Value Composite (MVC) of the NDVI was prepared from the stack of 8-day images. Altogether, 46 global mosaics of 8-day NDVI images available for year 2013 were used to create the final NDVI MVC image. For each pixel at the global scale, the period of the 8-day data in which the NDVI was at maximum was also recorded. The pixel-wise Shortwave Infrared (Swir) and Green reflectance values were drawn from the same period data when the NDVI was at maximum. In other words, the Swir and Green reflectance were chosen from the highest vegetation activity period. In this way, a three layered (Swir, NDVI, and Green) image was derived. BIC is the False Color Composite (FCC) image made by specially selected Swir, NDVI, and Green data as the red (R), green (G), and blue (B) bands, respectively. The RGB color displayed by the BIC corresponds to barren/urban, vegetation, and snow/water regions, respectively. Due to representation of the major biophysical components of the Earth's surface, it was termed as the Biophysical Image Composite (BIC). The procedure of deriving the Biophysical Image Composite (BIC) by using 8-day period MODIS time-series data is illustrated in Figure 1.

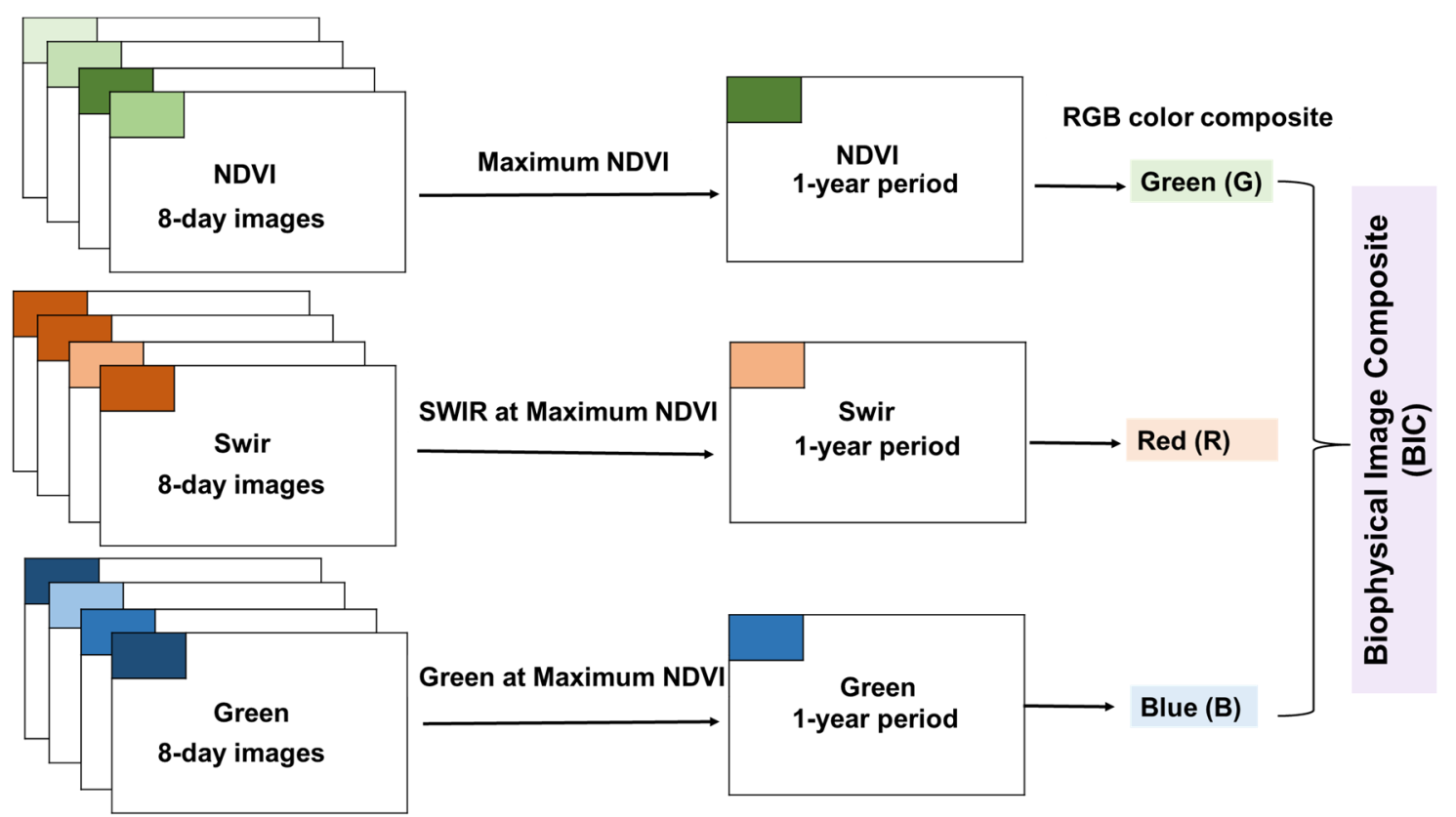

Figure 1. The procedure of deriving the Biophysical Image Composite (BIC) using time-series of 8-day period MODIS data. The shortwave infrared (Swir) and green (Green) reflectance values are chosen from the same time-period data when the Normalized Difference Vegetation Index (NDVI) was maximum. 


\subsection{Evaluation of Soil/Bareness Indexes}

Using all the MCD43A4 product data of year 2013, the existing soil/bareness indexes (NDSI, NDSI2, and NDBI) were calculated for each 8-day period. The thermal data required for the calculation of NDBI was obtained from MODIS MODTBGA and MYDTBGA products [21]. Based on MODTBGA and MYDTBGA products, using all the thermal data (band 20, 3.660-3.840 $\mu \mathrm{m}$ ) available at daily $1 \mathrm{~km}$ resolution on sinusoidal grid (version 6) of year 2013, 8-day maximum value composites (MVCs) of the thermal data were prepared. The thermal data were resampled into $500 \mathrm{~m}$ resolution, and it was used together with the MCD43A4 product based shortwave infrared data (band 7, 2105-2155 nm) to calculate the NDBI for each 8-day period.

From the stack of 8-day global mosaics of the soil/bareness indexes, annual statistical values (minimum and maximum) were calculated and used for further analysis. The discriminative potential of the existing indexes at the global scale was assessed with the reference data. The discriminative ability of the soil/bareness indexes was evaluated with a non-linear Random Forests classifier [22,23] based confusion matrices computed with the validation data.

Globally distributed reference data of year 2013 belonging to four major land cover types, water/snow (permanent), vegetation (forests, shrubs, herbaceous, and croplands), urban built-up, and barren lands, were collected by visual interpretation of the MODIS based monthly true-color composite images and Google Earth based images. Altogether 500 reference polygons belonging to each class were collected. Out of $\sim 500$ reference polygons of each class, 5000 points that fall inside the polygons were randomly extracted and used as the reference data. Out of 5000 reference points of each class, 3750 points were randomly selected as the training data, whereas the remaining 1250 points were used as the validation data. The distribution of the reference points data used in the research is displayed in Figure 2.

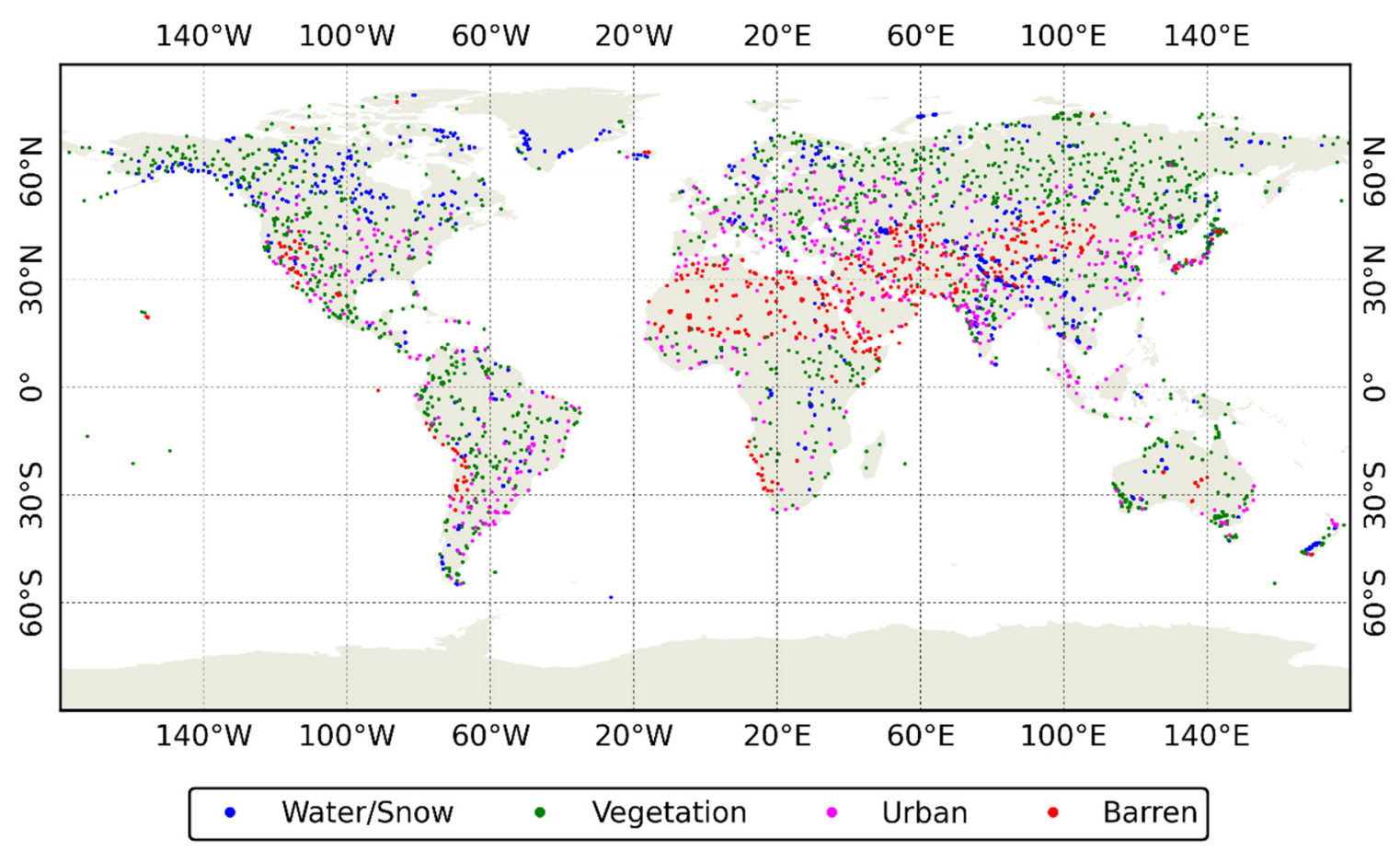

Figure 2. Geographical distribution of the reference points data used in the research.

\subsection{Global Mapping of Barren Lands}

The barren lands in the research are defined as the lands of exposed soil, sand, or rocks that are never covered by more than $10 \%$ vegetated cover of any type, such as forests, shrubs/herbs, and crops, during any time of the year, and are devoid of artificial materials such as built-up and 
impervious surface. Thus, the barren lands refer to the permanent barren lands over an annual temporal period. For practical reasons, up to $10 \%$ spatial coverage by vegetation is included into the barren lands. This definition also includes the fallow and waste lands if they do not cover more than $10 \%$ vegetation in any time of the year. The barren or sparsely vegetated lands as defined in this research are similar to the definition used by the MCD12Q1 product under the International Geosphere-Biosphere Programme (IGBP) classification scheme. The term barren land is used in the broad sense that it indicates not only large land masses devoid of vegetation such as deserts, but it also includes even small areas, for instance the eroded lands inside forests.

BIC were the only input data for the discrimination and mapping of the barren lands in the research. The Random Forests classifier-a supervised classification method which uses bootstrap aggregating (Bagging) to form an ensemble of trees by searching random subspaces from the given data, and best splitting of the nodes by minimizing the correlation between the trees-was used for discriminating the major land cover types with the support of reference data. However, since the discrimination of barren lands from urban built-up areas at the global scale is challenging with the multispectral data, nighttime lights data based urban built-up cover map produced in a previous study [24] was used to mask out the urban built-up areas into the BIC based barren lands estimates.

The accuracy of the global barren land cover map produced in the research was assessed by computing the confusion matrix with the validation data. The classification results were assessed by statistical metrics such as overall accuracy and kappa coefficient [25]. In addition, the resulted map was also compared with the existing MODIS Land Cover Type Product (MCD12Q1V051) of the corresponding year. The variation of the percentage barren land cover estimated by two maps in each continent was also compared.

\section{Results and Discussion}

\subsection{Performance of Soil/Bareness Indexes}

The performance of the existing soil/bareness indexes was assessed by carrying out a non-linear discriminant analysis. The Random Forests is a non-linear classifier that can handle highly non-linear interactions by searching random subspaces of the given data. The confusion matrices (Figure 3) computed between the Random Forests based predictions and validation data did not show satisfactory results as many barren and vegetated points were misclassified by the existing soil/bareness indexes.

The existing soil/bareness indexes were further evaluated by computing the overall accuracy and kappa coefficient (Table 1). Among the existing soil/bareness indexes tested, the NDSI-maximum (Figure $3 \mathrm{~b}$ ) and NDBI-minimum (Figure 3e) provided better results with the overall accuracy (kappa coefficient) of 0.65 (0.54) and $0.62(0.49)$, respectively.

The existing soil/bareness indexes (NDSI, NDSI2, and NDBI) were designed to be directly proportional to the barren land cover. The magnitude of the barren land cover varies with the season of a year; for instance, the same area full of bare soil in the dry season may be completely covered by herbaceous in the wet season. Therefore, choosing a right time data is crucial for discriminating the barren lands. A suitable time period can be known locally for better discrimination of barren lands. However, knowing such suitable time periods at the global scale is complicated due to irregular variation of the barren lands both spatially and seasonally. Therefore, an annual statistical metrics (minimum and maximum values) of the soil/bareness indexes were used in this evaluation. All these indexes use shortwave infrared (Swir) reflectance as one of the input data; however, the indexes (NDSI and NDBI) that used near infrared (Nir) reflectance and thermal infrared (Tir) brightness temperature performed better than the index that used the green reflectance (NDSI2). 


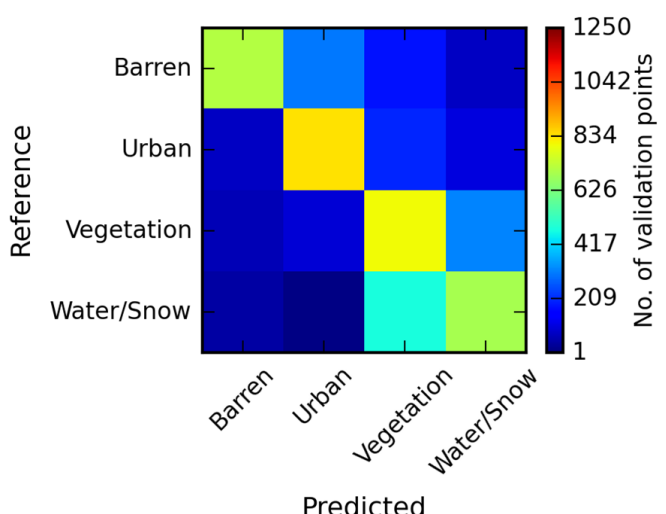

(a)

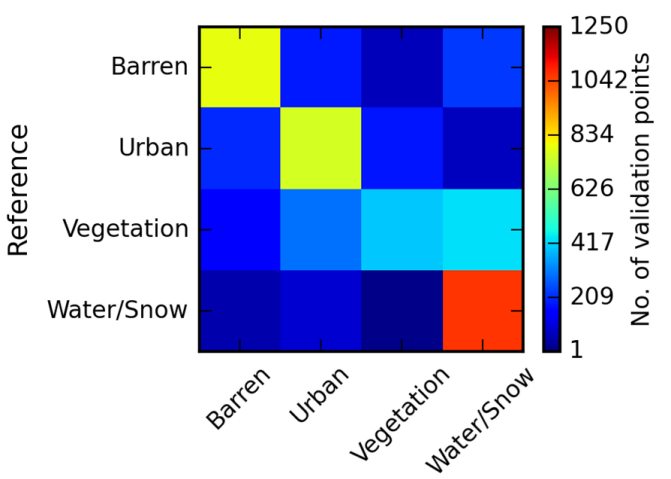

Predicted

(c)

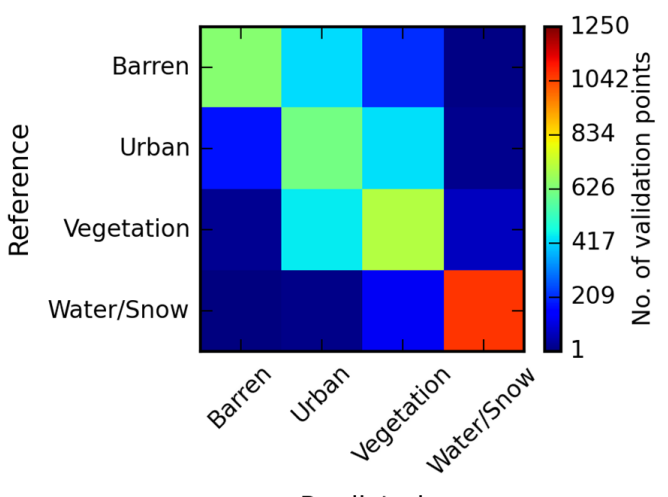

Predicted

(e)

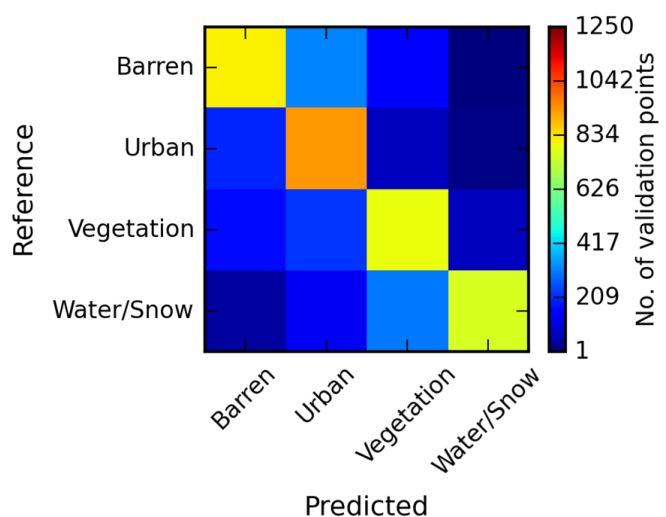

(b)

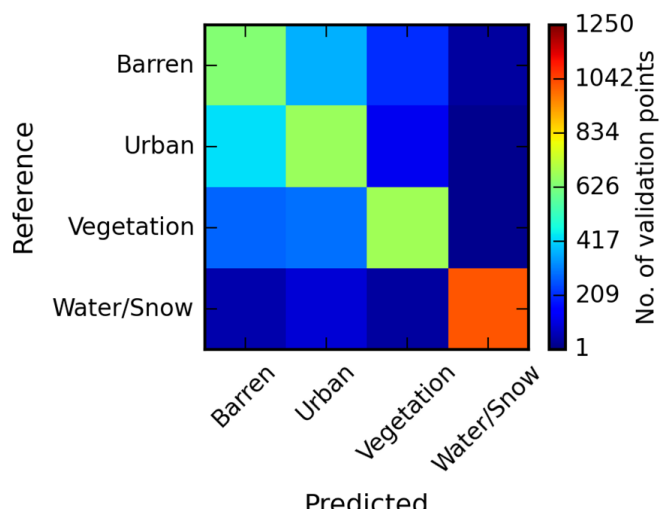

(d)

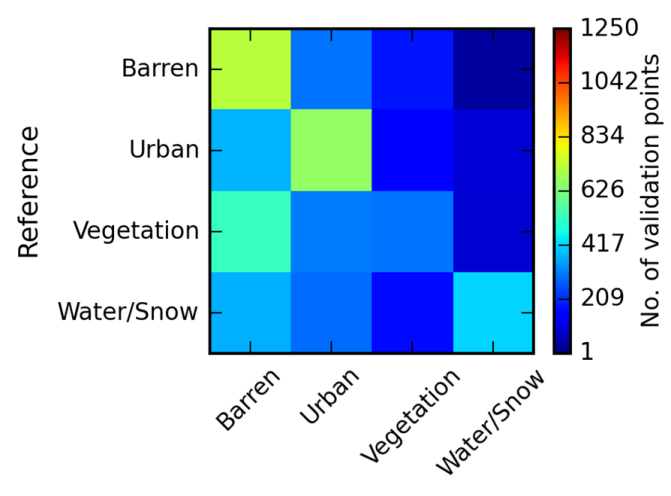

Predicted

(f)

Figure 3. Confusion matrix based discriminative performance of the existing soil/bareness indexes: (a) Normalized Difference Soil Index (NDSI-Minimum); (b) Normalized Difference Soil Index (NDSI-Maximum); (c) Normalized Difference Soil Index (NDSI2-Minimum); (d) Normalized Difference Soil Index (NDSI2-Maximum); (e) Normalized Difference Bareness Index (NDBI-Minimum); and (f) Normalized Difference Bareness Index (NDBI-Maximum).

\subsection{The BIC and Its Performance}

The BIC corresponding to the global land surface is displayed in Figure 4. The BIC has well distinguished the barren lands from vegetation and snow/water areas. The drastic contrast among the vegetation (green), barren land (red), and snow/water (blue) displayed by the BIC is crucial to the accurate extraction and mapping of the global barren lands. 


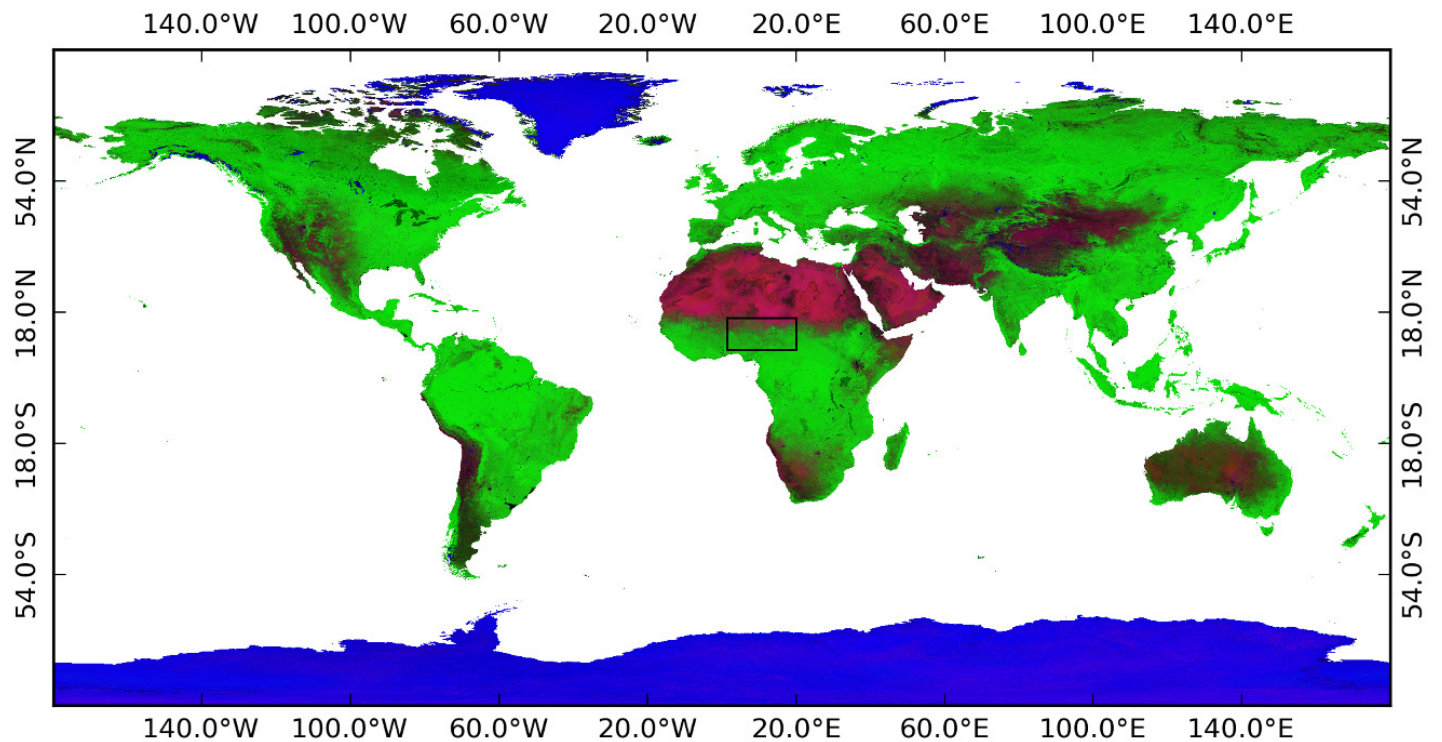

(a)

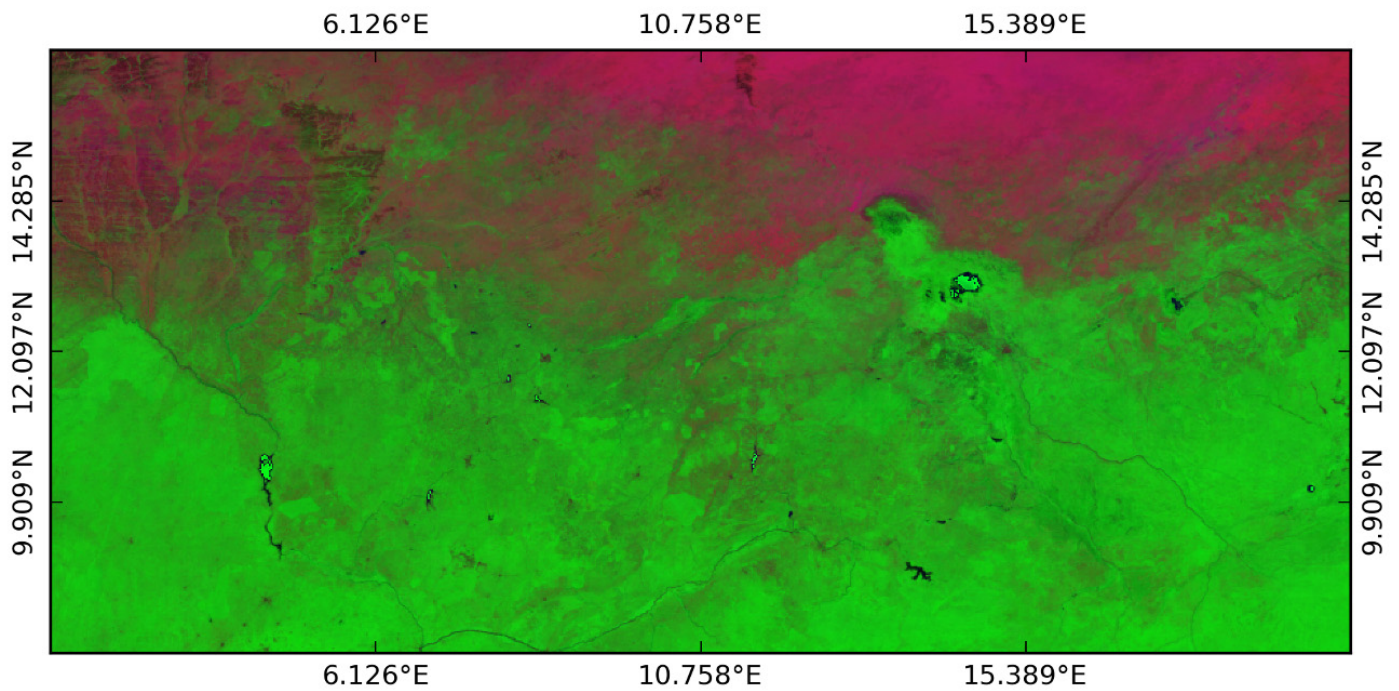

(b)

Figure 4. The Biophysical Image Composite (BIC) developed in the research showing contrast among the barren land (red), vegetation (green), and snow/water (blue): (a) displayed over the global land surface; and (b) zoomed in over the transition zone (black polygon) consisting of spare vegetation and barren lands.

The BIC in a transition zone between the barren land and sparse vegetation (Figure $4 \mathrm{~b}$ ) has also distinguished the barren lands efficiently with larger red and lower green reflectance values from the vegetation and snow/water areas. The quantification of the barren lands in a transition zone consisting of sparse vegetation is more difficult than in saturated barren areas where the contrast between the green and red components of the BIC is very high.

The performance of the BIC for the discrimination of barren lands at the global scale was assessed by computing the confusion matrix with the validation data which were not used for training the Random Forests model. The confusion matrix (Figure 5) shows that the BIC has provided a significant improvement to the existing indexes (Figure 3) on the discrimination of barren lands. 


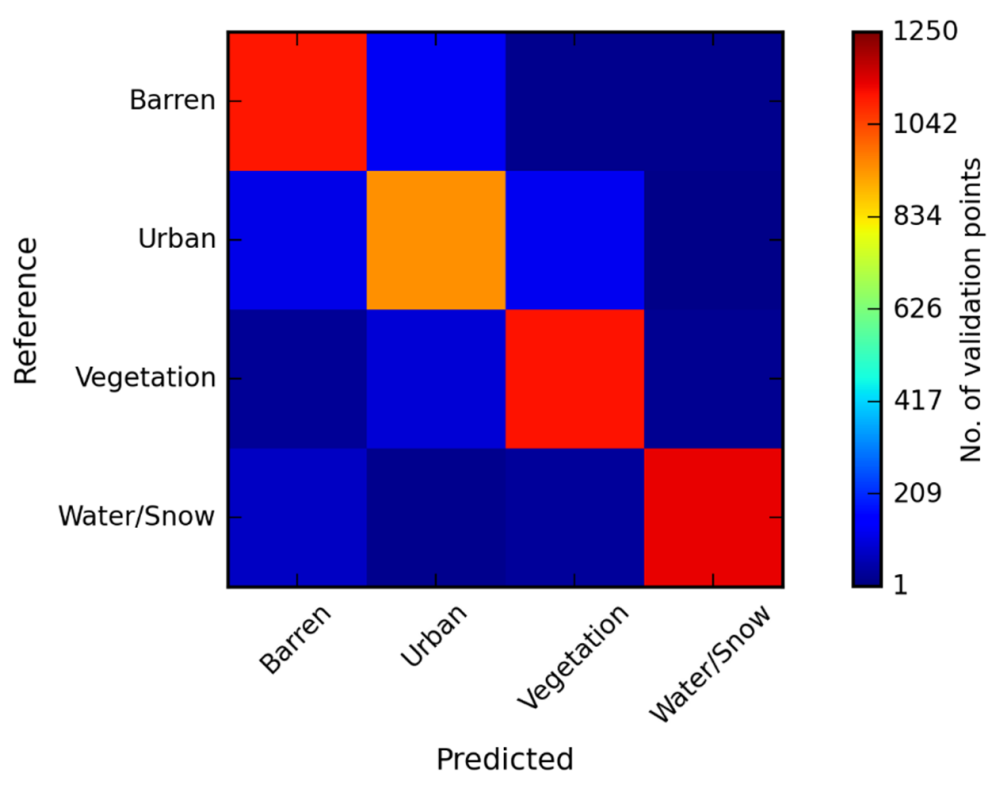

Figure 5. Confusion matrix of the BIC based classification of major land cover types.

The performance of the BIC for the discrimination of barren lands was further confirmed by calculating the overall accuracy and kappa coefficient. The BIC provided highest overall accuracy (0.86) and kappa coefficient $(0.80)$ among the indexes tested (Table 1$)$.

Table 1. Evaluation of the discriminative potential of different indexes based on overall accuracy and kappa coefficient.

\begin{tabular}{ccc}
\hline Indexes & Overall Accuracy & Kappa Coefficient \\
\hline NDSI (Min) & 0.62 & 0.49 \\
NDSI (Max) & 0.65 & 0.54 \\
NDSI2 (Min) & 0.60 & 0.47 \\
NDSI2 (Max) & 0.61 & 0.48 \\
NDBI (Min) & 0.62 & 0.49 \\
NDBI (Max) & 0.41 & 0.22 \\
BIC & 0.86 & 0.80 \\
\hline
\end{tabular}

The existing soil/bareness indexes were derived for the identification of the exposed soil or bareness pixels using a single image (without using time series dataset) in a small study area. The BIC, on the contrary, uses three bands (NDVI, Swir and Green) considering the phenological changes of the land surface. The BIC represents the scene as observed during the highest vegetation activity or the greenest period. This means that even if an area has vegetation for a month and in the other 11 months vegetation is completely absent from the area, it is classified as vegetation and not as barren land. This criterion is important for mapping of the barren lands in several ways. For example, croplands are usually seen as barren lands during few days to several months in a year. However, the extraction and representation of the greenest period scene by the BIC is capable of classifying the cropland into the vegetation group. The highest vegetation activity dates varies with the geographical locations. The choice of the pixel values based on the highest NDVI represents the greenest scene which are not usually contaminated by the seasonal snowfall. The provision of the seasonal snow free composite is another consideration for the discrimination and mapping of the barren lands because most of the places receive seasonal snowfall varying from few days to several months in a year. The BIC is also useful for visual interpretation of the barren lands. The fractional cover of the barren (vegetation) lands determines the redness (greenness) of the BIC. 


\subsection{Global Barren Land Cover Map}

The global barren land cover map produced through the research is plotted in Figure 6. The previous study [24] based urban built-up mask was applied on the BIC based estimates of the bareen lands while producing the final map.

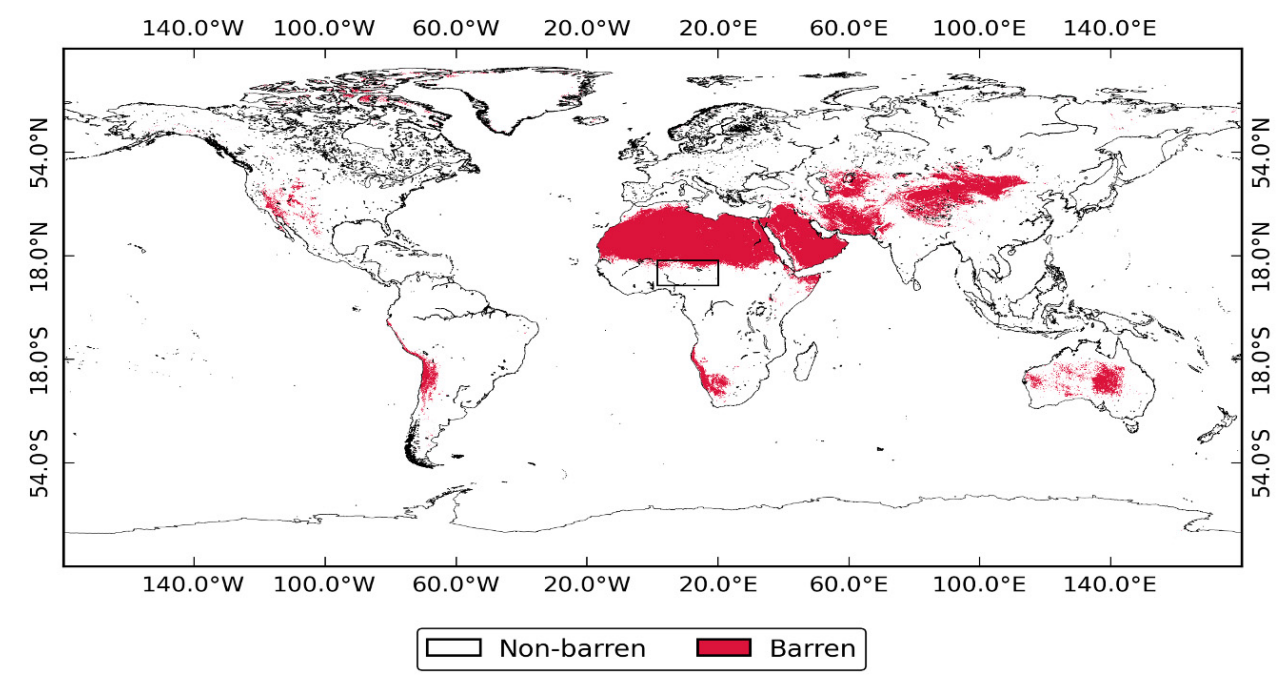

(a)

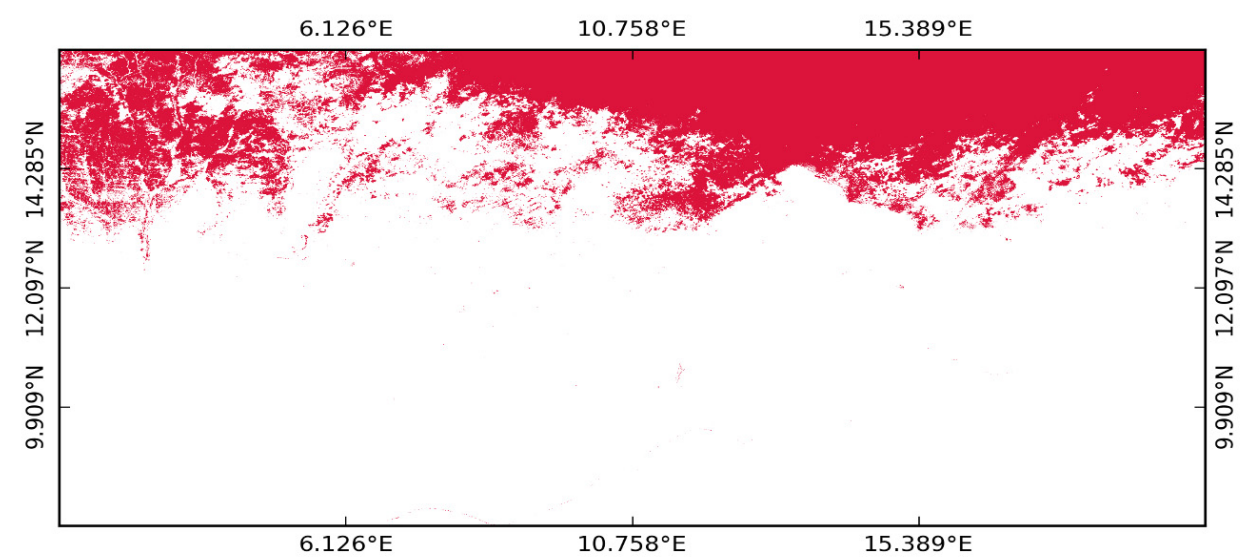

(b)

Figure 6. The barren land cover map produced through the research: (a) displayed over the global land surface; and (b) zoomed in over the transition zone (black polygon) consisting of sparse vegetation.

The barren land cover map produced in the research was compared with the existing MCD12Q1V051 product of year 2013. Both barren land cover maps have similar definition and were produced for the same year. However, these two maps exposed a substantial spatial variation on every continent (Figure 7).

The difference of percentage barren land cover between these two maps are $1.42 \%, 0.90 \%, 1.92 \%$, $12.16 \%$, and $0.27 \%$ in Africa, Eurasia, North America, Oceania, and South America, respectively. The highest discrepancy $(12.16 \%)$ noticed in Oceania was further examined by comparing it with the BIC. In Oceania, the MCD12Q1 2013 estimated very low coverage of the barren land, which is not seen by the BIC. Most of the red pixels corresponding to the barren lands in Figure 8a are missed by the MCD12Q1 2013 map (Figure 8b). 


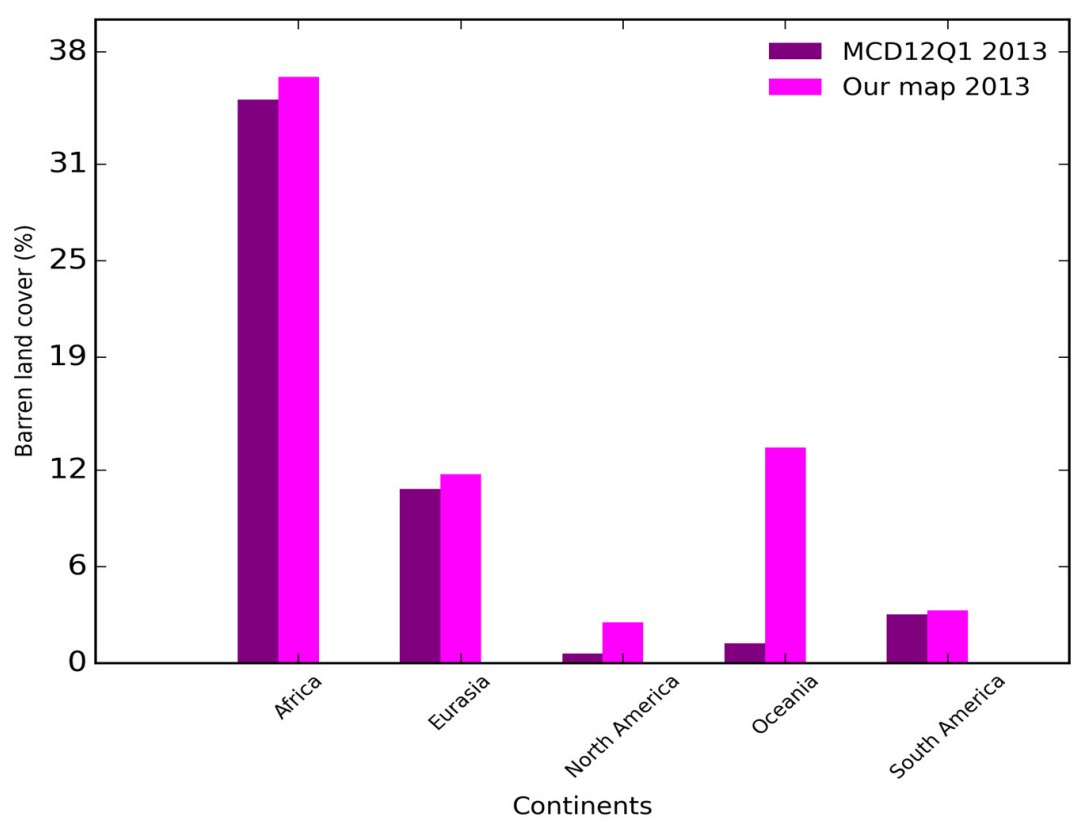

Figure 7. The variation of the barren land cover estimates by two maps for each continent.

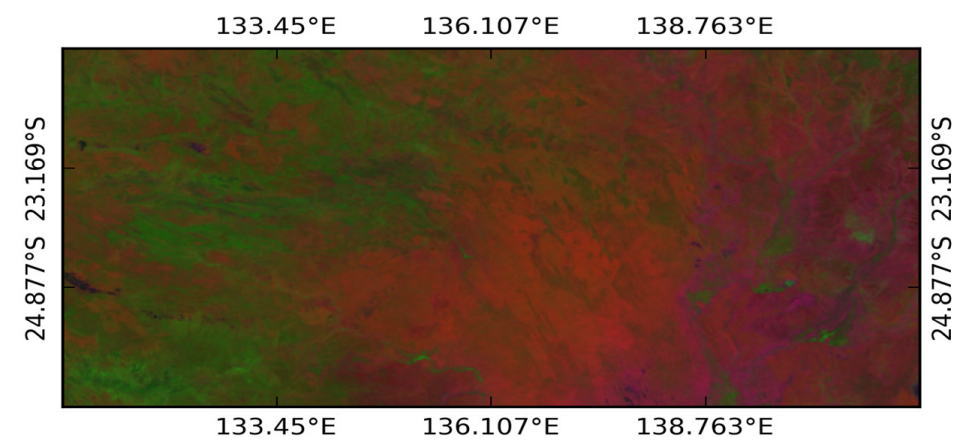

(a)

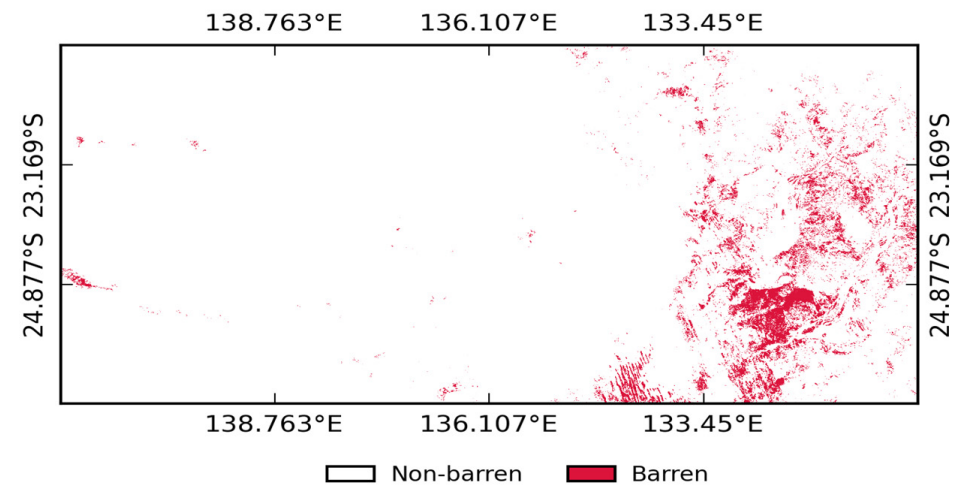

(b)

Figure 8. Missing of the genuine barren lands by the MCD12Q1 product: (a) BIC of year 2013; and (b) barren land cover estimated by the MCD12Q1V051 product of year 2013.

Using 5000 reference points data collected in the research, the statistical metrics (overall accuracy and kappa coefficient) of the two-label (barren and non-barren) classifications were calculated for our resulted map and MCD12Q1 map. As shown in Table 2, the overall accuracy and kappa coefficient of the resulted map is much higher than the existing MCD12Q1 map. 
Table 2. Comparison of barren land cover maps using overall accuracy and kappa coefficient.

\begin{tabular}{ccc}
\hline Maps & Overall Accuracy & Kappa Coefficient \\
\hline MCD12Q1 2013 & 0.87 & 0.61 \\
Our map 2013 & 0.92 & 0.83 \\
\hline
\end{tabular}

\section{Conclusions}

The paper presented three major issues to deal with global-scale extraction and mapping of the barren lands: (i) evaluation of existing indexes to map barren lands; (ii) developing a methodology for global mapping of barren lands and assessing its accuracy; and (iii) comparison of mapping result to other product available globally. The high variability of the barren lands in terms of the seasonal and spatial scale creates many challenges to the quantification of the barren land cover accurately at the global scale. The existing soil/bareness indexes derived and parameterized exclusively at the local scale could not represent the highly dynamic attributes of the barren lands everywhere in the globe satisfactorily. The peculiar attributes of the global barren lands was captured by developing a special image compositing technique that utilizes the greenest scene information from a time-series of the multispectral satellite data. The resultant imagery called the Biophysical Image Composite (BIC) provided a drastic contrast of the barren lands from the vegetation and water/snow areas. Achieving such drastic contrast is one significant improvement of the BIC that is crucial for discriminating a variety of barren lands distributed globally. The global-scale barren land cover was extracted and mapped by applying a non-linear supervised classifier (Random Forests) on the BIC. A new global map of the barren lands of year 2013 was produced and validated with the reference data. The comparison of the resultant map with the existing map of the same year with similar definition showed a substantial discrepancy. The large discrepancy between the estimates of barren land cover due to methodological variation highlights the importance of the BIC based approach for standardizing the global scale estimates of the bare land cover. Since the BIC has strong base of retrieving the barren lands by considering the highest vegetation activity period and avoiding signals from seasonal snows, it can overcome the uncertainties associated with the quantification of the barren land cover. The BIC is expected to contribute to the seasonal and annual biophysical change analysis of the Earth's surface as well.

Author Contributions: Ram C. Sharma conceived and designed the research, performed analyses, and wrote manuscript. Ryutaro Tateishi and Keitarou Hara revised the manuscript. All authors contributed and approved final manuscript before submission.

Conflicts of Interest: The authors declare no conflict of interest.

\section{References}

1. UN General Assembly. Transforming Our World: The 2030 Agenda for Sustainable Development; The Global Initiative Against Transnational Organized Crime: Geneva, Switzerland, 2015.

2. Prospero, J.M.; Ginoux, P.; Torres, O.; Nicholson, S.E.; Gill, T.E. Environmental characterization of global sources of atmospheric soil dust identified with the Nimbus 7 Total Ozone Mapping Spectrometer (TOMS) absorbing aerosol product. Rev. Geophys. 2002, 40,1-2. [CrossRef]

3. Engelstädter, S.; Kohfeld, K.E.; Tegen, I.; Harrison, S.P. Controls of dust emissions by vegetation and topographic depressions: An evaluation using dust storm frequency data. Geophys. Res. Lett. 2003. [CrossRef]

4. Kim, D.; Chin, M.; Bian, H.; Tan, Q.; Brown, M.E.; Zheng, T.; Kucsera, T. The effect of the dynamic surface bareness on dust source function, emission, and distribution. J. Geophys. Res. Atmos. 2013, 118, 871-886. [CrossRef]

5. Twomey, S.A.; Piepgrass, M.; Wolfe, T.L. An assessment of the impact of pollution on global cloud albedo. Tellus 1984. [CrossRef]

6. Charlson, R.J.; Schwartz, S.E.; Hales, J.M.; Cess, R.D.; Coakley, J.A.; Hansen, J.E.; Hofmann, D.J. Climate forcing by anthropogenic aerosols. Science 1992, 255, 423-430. [CrossRef] [PubMed] 
7. Hansen, J.; Sato, M.; Lacis, A.; Ruedy, R. The missing climate forcing. Philos. Trans. R. Soc. Lond. B Biol. Sci. 1997, 352, 231-240. [CrossRef]

8. Chin, M.; Diehl, T.; Ginoux, P.; Malm, W. Intercontinental transport of pollution and dust aerosols: Implications for regional air quality. Atmos. Chem. Phys. 2007, 7, 5501-5517. [CrossRef]

9. Seaton, A.; Godden, D.; MacNee, W.; Donaldson, K. Particulate air pollution and acute health effects. Lancet 1995, 345, 176-178. [CrossRef]

10. Mills, N.L.; Donaldson, K.; Hadoke, P.W.; Boon, N.A.; MacNee, W.; Cassee, F.R.; Newby, D.E. Adverse cardiovascular effects of air pollution. Nat. Clin. Pract. Cardiovasc. Med. 2009, 6, 36-44. [CrossRef] [PubMed]

11. Rogers, A.S.; Kearney, M.S. Reducing signature variability in unmixing coastal marsh Thematic Mapper scenes using spectral indices. Int. J. Remote Sens. 2004, 25, 2317-2335. [CrossRef]

12. Zhao, H.; Xiaoling, C. Use of normalized difference bareness index in quickly mapping bare areas from TM/ETM+. In Proceedings of the IGARSS '05, Seoul, Korea, 25-19 July 2005.

13. Li, S.; Chen, X. A new bare-soil index for rapid mapping developing areas using LANDSAT 8 data. Int. Arch. Photogramm. Remote Sens. Spat. Inf. Sci. 2014, 40, 139-145. [CrossRef]

14. Deng, Y.; Wu, C.; Li, M.; Chen, R. RNDSI: A ratio normalized difference soil index for remote sensing of urban/suburban environments. Int. J. Appl. Earth Obs. Geoinf. 2015, 39, 40-48. [CrossRef]

15. Friedl, M.A.; Sulla-Menashe, D.; Tan, B.; Schneider, A.; Ramankutty, N.; Sibley, A.; Huang, X. MODIS Collection 5 global land cover: Algorithm refinements and characterization of new datasets. Remote Sens. Environ. 2010, 114, 168-182. [CrossRef]

16. Tateishi, R.; Hoan, N.T.; Kobayashi, T.; Alsaaideh, B.; Tana, G.; Phong, D.X. Production of global land cover data-GLCNMO2008. J. Geogr. Geol. 2014, 6, 99-123. [CrossRef]

17. Arino, O.; Ramos-Perez, J.J.; Kalogirou, V.; Bontemps, S.; Defourny, P.; Van Bogaert, E. Global land cover map for 2009 (GlobCover 2009). PANGAEA 2009. [CrossRef]

18. Schaaf, C.B.; Gao, F.; Strahler, A.H.; Lucht, W.; Li, X.; Tsang, T.; Roy, D. First operational BRDF, albedo nadir reflectance products from MODIS. Remote Sens. Environ. 2002, 83, 135-148. [CrossRef]

19. Rouse, J., Jr.; Haas, R.; Schell, J.; Deering, D. Monitoring Vegetation Systems in the Great Plains with ERTS; NASA: Washington, DC, USA, 1974.

20. Tucker, C.J. Red and photographic infrared linear combinations for monitoring vegetation. Remote Sens. Environ. 1979, 8, 127-150. [CrossRef]

21. MODTBGA MODIS/Terra Thermal Bands Daily L2G-Lite Global 1km SIN Grid V006. Available online: http:/ / doi.org/10.5067/MODIS/MODTBGA.006 (accessed on 29 November 2016).

22. Breiman, L.; Friedman, J.H.; Olshen, R.A.; Stone, C.J. Classification and Regression Trees; Wadsworth: Belmont, CA, USA, 1984.

23. Breiman, L. Random forests. Mach. Learn. 2001, 45, 5-32. [CrossRef]

24. Sharma, R.C.; Tateishi, R.; Hara, K.; Gharechelou, S.; Iizuka, K. Global mapping of urban built-up areas of year 2014 by combining MODIS multispectral data with VIIRS nighttime light data. Int. J. Digit. Earth 2016, 23, 1-17. [CrossRef]

25. Cohen, J. A Coefficient of agreement for nominal scales. Educ. Psychol. Meas. 1960, 20, 37-46. [CrossRef]

(C) 2016 by the authors; licensee MDPI, Basel, Switzerland. This article is an open access article distributed under the terms and conditions of the Creative Commons Attribution (CC-BY) license (http://creativecommons.org/licenses/by/4.0/). 